\title{
Effect of timing of umbilical cord clamping on anaemia at 8 and 12 months and later neurodevelopment in late pre-term and term infants; a facility-based, randomized- controlled trial in Nepal
}

\author{
Ashish KC $\mathrm{KC}^{1,2^{*}}$, Mats Målqvist ${ }^{1}$, Nisha Rana ${ }^{1,3}$, Linda Jarawka Ranneberg ${ }^{4}$ and Ola Andersson ${ }^{1}$
}

\begin{abstract}
Background: Delayed cord clamping at birth has shown to benefit neonates with increased placental transfusion leading to higher haemoglobin concentrations, additional iron stores and less anaemia later in infancy, higher red blood cell flow to vital organs and better cardiopulmonary adaptation. As iron deficiency in infants even without anaemia has been associated with impaired development, delayed cord clamping seems to benefit full term infants also in regions with a relatively low prevalence of iron deficiency anaemia. In Nepal, there is a high anaemia prevalence among children between 6 and 17 months (72-78\%). The objective of the proposed study is to evaluate the effects of delayed and early cord clamping on anaemia (and haemoglobin level) at 8 and 12 months, ferritin at 8 and 12 months, bilirubin at 2-3 days, admission to Neonatal Intensive Care Unit (NICU) or special care nursery, and development at 12 and 18-24 months of age.
\end{abstract}

Methods/design: A randomized, controlled trial comparing delayed and early cord clamping will be implemented at Paropakar Maternity and Women's Hospital in Kathmandu, Nepal. Pregnant woman of gestational age 34-41 weeks who deliver vaginally will be included in the study. The interventions will consist of delayed clamping of the umbilical cord ( $\geq 180 \mathrm{~s}$ after delivery) or early clamping of the umbilical cord ( $\leq 60 \mathrm{~s}$ ). At 8 and 12 months of age, infant's iron status and developmental milestones will be measured.

Discussion: This trial is important to perform because, although strong indications for the beneficial effect of delayed cord clamping on anaemia at 8 to 12 months of age exist, it has not yet been evaluated by a randomized trial in this setting. The proposed study will analyse both outcome as well as safety effects. Additionally, the results may not only contribute to practice in Nepal, but also to the global community, in particular to other low-income countries with a high prevalence of iron deficiency anaemia.

Trial registration: Clinical trial.gov NCT02222805. Registered August 192014.

\footnotetext{
* Correspondence: aaashis7@yahoo.com

'Department of Women's and Children's Health, International Maternal and

Child Health, Uppsala University, Uppsala SE-751 85, Sweden

${ }^{2}$ United Nations Children's Fund (UNICEF), Kathmandu, Nepal

Full list of author information is available at the end of the article
} 


\section{Background}

At the time of birth, the infant is still attached to the placenta via the umbilical cord. The infant is usually separated from the placenta by clamping the cord with two clamps, and cutting between the clamps. This task takes place during the third stage of labour, which is the period of time from the birth of the infant to the delivery of the placenta [1].

Active management of the third stage of labour has been described in a recent World Health Organization (WHO) report as the "cornerstone" of obstetric and midwifery practice during the latter part of the 20th century [2]. Active management has involved the clinician intervening in the process of placental delivery through three interrelated practices: the administration of an uterotonic drug; early cord clamping and cutting; and controlled traction of the umbilical cord.

Early cord clamping has generally been advised to be completed within the first $30 \mathrm{~s}$ after birth, regardless of whether cord pulsation has ceased [3]. Due to evidence shown in the last decade, recent guidelines for active management of the third stage of labour no longer recommend immediate cord clamping [4], but changes in practice are still questioned [5] and policies in hospitals are rare [6].

Delayed clamping allows time for a transfer of the foetal blood in the placenta to the infant at the time of birth. This placental transfusion can provide the infant with an additional $40 \%$ more blood volume [7]. The amount of blood transferred to the infant depends on when the cord is clamped and at what level the infant is held prior to clamping [8]. Neonatal benefits associated with this increased placental transfusion include higher haemoglobin concentrations, additional iron stores and less anaemia in early infancy and better cardiopulmonary adaptation $[1,9,10]$.

Delayed cord clamping has, however, been linked to an increase in the incidence of jaundice which, in severe cases, could have longer-term effects on the health and development of the infant $[1,11]$.

Previous studies performed by the principal investigator in a high-income country have shown that delayed cord clamping, compared with early clamping, resulted in a reduced prevalence of neonatal anaemia [12]. Furthermore, delayed cord clamping improved iron status and reduced the prevalence of iron deficiency (ID) in infants at four months of age without demonstrable adverse effects [12-14]. As ID in infants even without anaemia has been associated with impaired development $[15,16]$, delayed cord clamping seems to benefit full term infants even in regions with a relatively low prevalence of ID anaemia [12].

The improved iron stores at four to six months after delayed cord clamping suggest that ID anaemia could be reduced at eight to twelve months of age, but this could not be shown in a later study by the principal investigators [17], possibly due to small sample size and low frequency of ID anaemia. However, delayed cord clamping was associated with improved fine motor function at 4 years of age [18]. Although ID anaemia is rare (3-9 \%) in high-income countries [19], the negative impact on children's health and development should not be underestimated. No randomized trial has evaluated the effect of delayed versus early cord clamping on infants after six months of age in a low-income country with high prevalence of ID and anaemia. As anaemia is associated with extensive health effects, such as stunting, fatigue and impaired neurodevelopment [20], reducing anaemia in infants is an urgent need globally. In an observational study from Peru, anaemia at eight months of age was evaluated in infants born before and after a hospital policy change from early to delayed cord clamping. The study resulted in a significant reduction of anaemia by $16 \%$ (from 75 to $59 \%$ ) as well as a significantly higher level of haemoglobin among infants [21].

In Nepal, there is a high prevalence of anaemia among children aged 6-17 months (72-78 \%) [22]. Approximately $50 \%$ of all anaemia among pre-schoolers can be contributed to ID [23]. By performing the planned study in a country with high anaemia prevalence, we aim to evaluate any significant effects on haemoglobin levels and neurodevelopment outcomes after different timing of umbilical cord clamping in this high-risk population.

\section{Study objective}

To evaluate the effects of delayed and early cord clamping on:

1. Anaemia (and haemoglobin level) at 8 and 12 months

2. Ferritin at 8 and 12 months

3. Bilirubin at 2-3 days

4. Admission to the NICU or special care nursery

5. Development at 12 and 18-24 months of age.

\section{Primary outcome}

The primary outcome will be pre-specified infant haemoglobin at 8 month of age.

Anaemia will be defined as altitude corrected haemoglobin less than $110 \mathrm{~g} / \mathrm{L}$.

\section{Secondary outcomes}

The secondary outcomes will be

- Haemoglobin at 12 months

- Ferritin at 8 and 12 months; definition iron deficiency as ferritin less than $12 \mu \mathrm{g} / \mathrm{L}$ 
- Iron deficiency anaemia at 8 and 12 months, defined as both ferritin and haemoglobin below the respective cut offs

- Other outcomes will be hyperbilirubinemia at discharge, breast-feeding and morbidity during the first six months of life and psychomotor development at 12 months.

\section{Methods}

\section{Study design and participants}

This will be a randomized control trial in a hospital of Nepal with two parallel groups (1:1 ratio), delayed cord clamping $(\geq 180$ s) and early cord clamping $(\leq 60 \mathrm{~s})$. The study will be conducted in Paropakar Maternity and Women's Hospital, a public funded tertiary centre for obstetric and gynaecological services in Kathmandu, Nepal.

In the hospital there are two separated delivery departments, high risk-labour room (LR) and low riskMaternal and Neonatal Service Center (MNSC). At admission, according to the hospital protocol, the pregnant women are screened by an obstetrician who made the decision to which department the women will be transferred.

The hospital criteria for admission to MNSC areuncomplicated pregnancies, no complication at the time of admission and healthy mothers (no clinical history of hypertension, infection, diabetes, chronic medical condition), expected vaginal delivery, gestational age between 34 and 41 weeks and singleton pregnancy.

Women will be eligible to participate in the study if they are assigned to MNSC. The exclusion criteria will be serious congenital malformation, syndromes, or the other congenital disease that could affect the outcome measures. Written consent will be obtained from the women who were eligible and willing to participate (Fig. 1).

\section{Randomization}

The principal investigator will prepare a random list using random digit generator in Microsoft excel and will not have clinical involvement in the trial. Following this, he will prepare sequentially numbered, opaque envelopes and put in the colour cards with details of the allocated group and sealed the envelopes.

These will be kept at the research office and will be brought in the delivery unit before randomization.

Randomization will take place a few minutes before delivery when the nurse-midwife considered vaginal delivery is imminent. To allocate the women into treatment group, the surveillance officer $(\mathrm{SO})$ will open the next consecutively numbered envelope and inform the nurse-midwife of the assigned treatment. The used colour card and envelope will be discarded.

\section{Surveillance protocol}

Before the study period, early clamping was predominately practiced at the hospital. During the study period, surveillance officers $(\mathrm{SO})$ are stationed $24 \mathrm{~h}$ a day at three stations, the reception, the delivery ward, and the postnatal wards. SO are all trained nurse-midwives.

As the pregnant woman arrives at the hospital, she will receive written information about the study in the reception. A SO will then approach the woman and ask for her consent to participate in the study.

If the woman agrees, she will sign the consent form and the $\mathrm{SO}$ stationed at the reception will register the information needed according to protocol. The woman's labour will be managed by following the hospital's ordinary routine until she is transferred to the delivery ward, where the randomisation takes place. The SO stationed at the delivery ward will pair the woman with a sealed, numbered, opaque envelope containing the treatment allocation and show this to the nurse-midwife conducting the delivery.

\section{Intervention}

When delivery is imminent (expected within $10 \mathrm{~min}$ ), the nurse-midwife will open the sealed, numbered, opaque envelope to reveal the treatment allocation. The interventions consist of delayed clamping of the umbilical cord ( $\geq 180 \mathrm{~s}$ after delivery) or early clamping of the umbilical cord $(\leq 60 \mathrm{~s})$. The SO will measure the time from complete delivery of the baby until the first clamp is placed on the umbilical cord with a stopwatch. All other aspects of obstetric care will be managed according to standard practice at the hospital. Should the infant need resuscitation, the umbilical cord will be clamped and cut and the infant will be carried to the resuscitation table for further handling. In both groups, oxytocin will be given to the mother after the umbilical cord is clamped. All staff in the delivery unit will be trained in the study procedures before the trial is started.

\section{Follow-up}

After delivery, the babies will be cared for according to standard clinical routines, and early breast-feeding will be encouraged. As part of the study, the nurse-midwife will assess the infant at 1 and $6 \mathrm{~h}$, to see whether the baby has been breastfed Infants will stay at the postnatal ward with their mothers for two or three days after delivery, except for those well babies whose mothers prefer to leave the hospital earlier and infants who require admission to the neonatal unit. The SO stationed at the postnatal ward will perform transcutaneous bilirubin measurements when child and mother are discharged from the hospital, as well as 24 and $48 \mathrm{~h}$ after delivery if possible. The following information will be collected from maternal healthcare records: background information of 


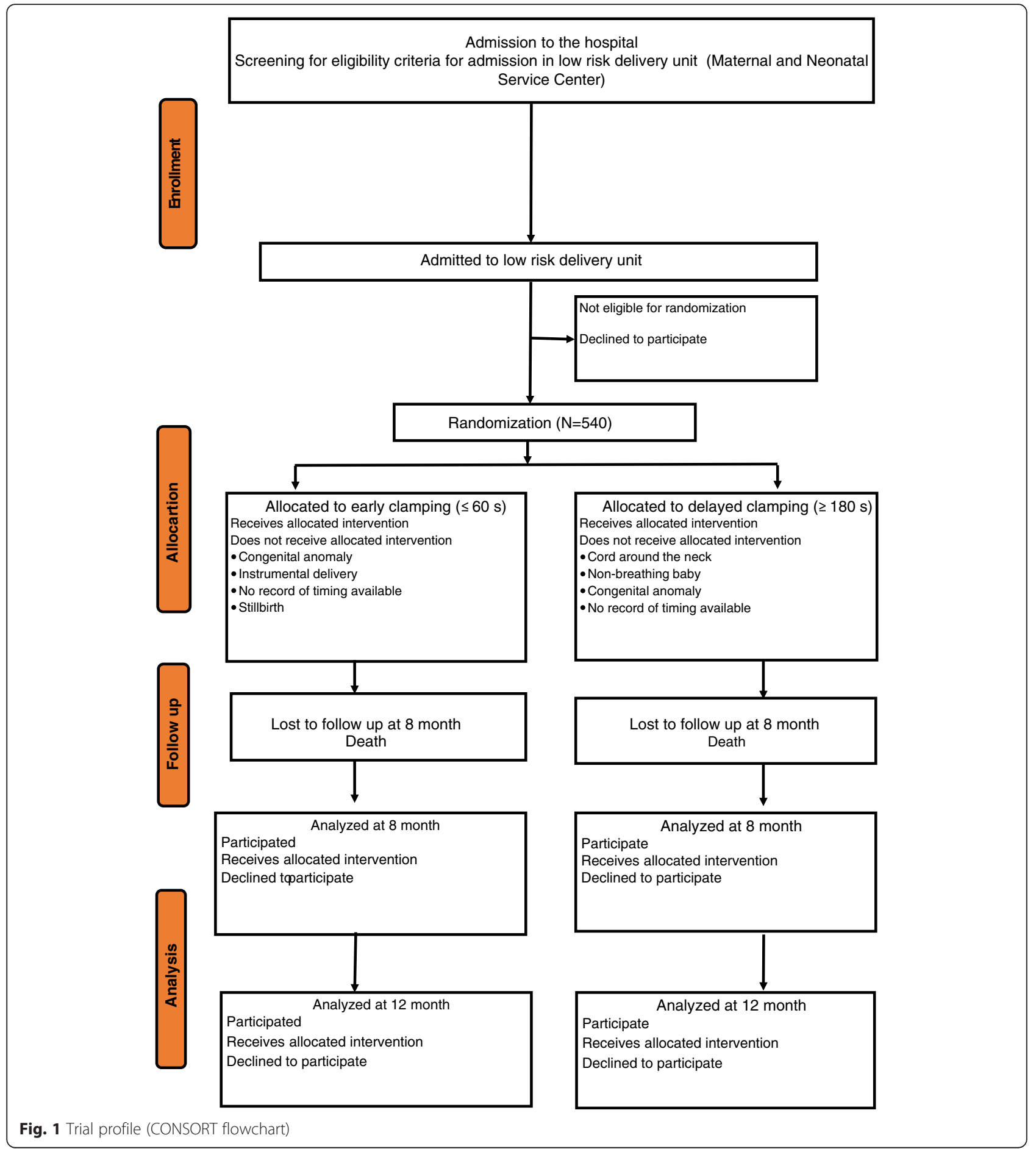

the mother's age and parity, babies' weight, gestational age and Apgar score.

Monthly, up to 12 months of age, a SO will call the family and ask questions regarding infections, breastfeeding and immunizations of the infant.

At 8 and 12 months of age, infants will be scheduled for a follow-up visit including blood sampling (haemoglobin and ferritin). Venous blood sampling will be performed. Mother's will be interviewed about the infant's feeding practice.

At 12 months of age, the Ages \& Stages Questionnaire will be used to record infants' neurodevelopment. Parents will be assisted in answering the Ages \& Stages Questionnaire. 
If funding is obtained, the Bayley Scales of Infant and Toddler Development, third edition will be used to examine children at 18-24 months of age.

\section{Blinding}

The study design precluded either the mother giving birth or the nurse-midwife performing the intervention being blinded. Physicians performing neonatal examinations, staff members responsible for collection of blood samples and background data, and laboratory staff performing analyses of blood samples will be blinded to each infant's allocation group.

\section{Sample size}

The sample size for the primary outcome at eight months was estimated in order to find a difference of $15 \%$ (70 versus $55 \%$ ) in the prevalence of anaemia between the two randomization groups with a power of $80 \%$ and a type I error rate of .05. Using Fisher's exacttest to analyse outcome data, a group size of 176 would be needed. Taking into account an attrition rate of $35 \%$ we calculated that 270 newborns should be included in each group, i.e. a total of 540 .

\section{Timeline}

The study will begin on October 2, 2014 with the expected enrolment of the 540 participants within 45 to 60 days of the project start date.

\section{Data management}

The SO will fill up and assess data records. The two research managers will verify all record forms with the primary source of data. A data entry officer will re-check them for discrepancies before entering the data in computers. The quality control team from Uppsala University will provide oversight to ensure quality of data collection and to avoid data loss. A protocol for data tracking will be followed. All cases will be analysed on an intention to treat basis.

The Census and Survey Processing System (CSPro), a public domain software package developed and supported by the U.S. Census Bureau and ICF Macro, will be used for quality data management. CSPro is interfaced with SPSS (originally, Statistical Package for the Social Sciences, 20), which will be used for statistical analysis, data management (case selection, file reshaping, creating derived data), and data documentation. Hard copies of records will be stored in a filing system in a secure room. Data will be checked for accuracy, consistency, and completeness in both CSPro and SPSS. An analysis plan will be developed in accordance with the reporting guidelines. A profile and comparison of key variables between groups at baseline will be presented.

\section{Ethical considerations}

All research involving newborn infants and small children needs careful ethical consideration, mainly since the subjects themselves cannot agree to whether they want to participate in the study or not. In particular, research that is not immediately beneficial for the patients needs special ethical consideration. The included infants are healthy full-term infants undergoing umbilical cord clamping, which is a standard procedure after birth. The possible benefit of the intervention (delayed cord clamping) for increasing iron stores and preventing infant anaemia is estimated to be higher than the risk of probable adverse effects, such as hyperbilirubinemia. Ethical approval has been sought and obtained from Nepal Health Research Council (Reg no. 76/2014) on 5 June 2014. The trial has been registered at clinicaltrial.gov with the registration number NCT 02222805 on August 19, 2014. Written informed parental consent will be obtained before the intervention is given, and parents can withdraw from the study at any time without any need for explanation.

\section{Discussion}

Reducing ID among infants is important, as it is associated with impaired neurodevelopment [16]. With a high global prevalence of infant anaemia, delayed cord clamping has the potential to reduce infant anaemia and thereby improve infants' and children's health and development. In crude numbers, a reduction by $10 \%$ would mean an annual reduction of 60,000 infants with anaemia in Nepal. This trial is important to perform because, although strong indications for the beneficial effect of delayed cord clamping on anaemia at 8 to 12 months of age exist, it has not been evaluated by a randomized trial in a low-income setting with a high prevalence of ID and anaemia. By completion of the proposed study, both outcome as well as safety effects will be analysed. Additionally, the results may not only contribute to the practice in Nepal, but also to the global community, in particular to other low-income countries with a high prevalence of ID anaemia.

\section{Abbreviations \\ UNICEF: United Nation's Children's Fund; NICU: Neonatal Intensive Care Unit; NCT: National Institute of Health Clinical Trial; WHO: World Health Organization; ID: iron deficiency; SO: surveillance officers; CSPro: Census and Survey Processing System; SPSS: Statistical Package for the Social Sciences.}

\section{Competing interests \\ The authors declare that they have no competing interests.}

\section{Authors' contributions}

$\mathrm{AK}, \mathrm{MM}$ and $\mathrm{OA}$ conceptualized and designed the study. AK and OA drafted the study protocol manuscript. MM, LJR, NR and RV contributed to the development of the protocol. All authors reviewed and approved the draft manuscript. 


\section{Acknowledgement}

We would like to acknowledge Prof. Uwe Ewald, Department of Women's and Children, Uppsala University for providing the input in the study design, Viktoria Nelin for language editing, Prof. Pushpa Chaudhary, Dr. Dhan Raj Aryal, Dr. Kamal Sharma, Prof. Geha Nath Baral, Dr. Sheela Verma, Prof. Kiran Bajracharya, Amar Nath Amatya and Maiya Manandhar for their help to finalize the protocol.

\section{Funding}

Funding for the study was provided through grants from the Swedish Society of Medicine, Sweden and Lilla Barnets fond, Sweden. The view expressed in the publication is that of authors and do not reflect the funding agency.

\section{Author details}

'Department of Women's and Children's Health, International Maternal and Child Health, Uppsala University, Uppsala SE-751 85, Sweden. ${ }^{2}$ United Nations Children's Fund (UNICEF), Kathmandu, Nepal. ${ }^{3}$ Paropakar Maternity and Women's Hospital, Kathmandu, Nepal. ${ }^{4}$ Department of Paediatrics, Hospital of Halland, Halmstad, Sweden.

\section{Received: 19 October 2014 Accepted: 8 March 2016}

Published online: 10 March 2016

\section{References}

1. McDonald SJ, Middleton P, Dowswell T, Morris PS. Effect of timing of umbilical cord clamping of term infants on maternal and neonatal outcomes. Cochrane Database Syst Rev. 2013;7:CD004074

2. WHO. In: Organization WH, editor. Recommendations for the Prevention and Treatment of Postpartum Haemorrhage. Geneva: World Health Organization; 2012.

3. McDonald SJ. Physiology and management of the third stage of labour. In Fraser D, Cooper M editor(s). Myles Textbook for Midwives. 14th Edition. Edinburgh: Churchill Livingstone, 2003.

4. Oladapo OT, Akinola OI, Fawole AO, Adeyemi AS, Adegbola O, Loto OM, Fabamwo AO, Alao MO, Sotunsa JO, Nigerian AG. Active management of third stage of labor: evidence versus practice. Acta Obstet Gynecol Scand. 2009;88(11):1252-60.

5. Committee on Obstetric Practice ACoO, Gynecologists. Committee Opinion No.543: Timing of umbilical cord clamping after birth. Obstet Gynecol. 2012;120(6):1522-6.

6. Jelin AC, Kuppermann M, Erickson K, Clyman R, Schulkin J. Obstetricians' attitudes and beliefs regarding umbilical cord clamping. J Matern Fetal Neonatal Med. 2014;27(14):1457-61.

7. Airey RJ, Farrar D, Duley L. Alternative positions for the baby at birth before clamping the umbilical cord. Cochrane Database Syst Rev. 2010;10:CD007555

8. Yao AC, Lind J. Placental transfusion. Am J Dis Child. 1974;127(1):128-41.

9. Hutton EK, Hassan ES. Late vs early clamping of the umbilical cord in fullterm neonates: systematic review and meta-analysis of controlled trials. JAMA. 2007;297(11):1241-52.

10. Bhatt $\mathrm{S}$, Alison BJ, Wallace EM, Crossley KJ, Gill AW, Kluckow M, te Pas AB, Morley CJ, Polglase GR, Hooper SB. Delaying cord clamping until ventilation onset improves cardiovascular function at birth in preterm lambs. J Physiol. 2013;591 (Pt 8):2113-26.

11. Prendiville W ED. Care during the third stage of labour. In: Effective Care in Pregnancy and Childbirth. Edited by Chalmers I EM, Keirse MJNC editor(s), vol. 1145-69. Oxford: Oxford University Press, 1989; 1989.

12. Andersson $\mathrm{O}$, Hellstrom-Westas $\mathrm{L}$, Andersson D, Domellof M. Effect of delayed versus early umbilical cord clamping on neonatal outcomes and iron status at 4 months: a randomised controlled trial. BMJ. 2011;343:d7157.

13. Andersson O, Hellstrom-Westas L, Andersson D, Clausen J, Domellof M. Effects of delayed compared with early umbilical cord clamping on maternal postpartum hemorrhage and cord blood gas sampling: a randomized trial. Acta Obstet Gynecol Scand. 2013:92(5):567-74.

14. Andersson O, Domellof M, Andersson D, Hellstrom-Westas L. Effects of delayed cord clamping on neurodevelopment and infection at four months of age: a randomised trial. Acta Paediatr. 2013;102(5):525-31.

15. Radlowski EC, Johnson RW. Perinatal iron deficiency and neurocognitive development. Front Hum Neurosci. 2013;7:585
16. Lozoff B, Beard J, Connor J, Barbara F, Georgieff M, Schallert T. Long-lasting neural and behavioral effects of iron deficiency in infancy. Nutr Rev. 2006; 64(5 Pt 2):S34-43. discussion S72-91.

17. Andersson O, Domellof M, Andersson D, Hellstrom-Westas L. Effect of delayed vs early umbilical cord clamping on iron status and neurodevelopment at age 12 months: a randomized clinical trial. JAMA Pediatr. 2014;168(6):547-54.

18. Andersson O, Lindquist B, Lindgren M, Stjernqvist K, Domellöf M, HellströmWestas L. Effect of delayed cord clamping on neurodevelopment at 4 years of age: A randomized clinical trial. JAMA Pediatr. 2015;169(7):631-8.

19. Domellof M, Braegger C, Campoy C, Colomb V, Decsi T, Fewtrell M, Hojsak I, Mihatsch W, Molgaard C, Shamir R et al. Iron requirements of infants and toddlers. J Pediatr Gastroenterol Nutr. 2014:58(1):119-29.

20. Kapil U, Bhavna A. Adverse effects of poor micronutrient status during childhood and adolescence. Nutr Rev. 2002;60(5 Pt 2):S84-90.

21. Gyorkos TW, Maheu-Giroux M, Blouin B, Creed-Kanashiro H, Casapia M, Aguilar E, Silva H, Joseph SA, Penny ME. A hospital policy change toward delayed cord clamping is effective in improving hemoglobin levels and anemia status of 8-month-old Peruvian infants. J Trop Pediatr. 2012:58(6):435-40.

22. Ministry of Health \& Population, New Era, ICF Macro, USAID. Nepal Demographic and Health Survey 2011. Kathmandu: New Era; 2011.

23. McLean E, Cogswell M, Egli I, Wojdyla D, de Benoist B. Worldwide prevalence of anaemia, WHO Vitamin and Mineral Nutrition Information System, 1993-2005. Public Health Nutr. 2009;12(4):444-54.

\section{Submit your next manuscript to BioMed Central and we will help you at every step:}

- We accept pre-submission inquiries

- Our selector tool helps you to find the most relevant journal

- We provide round the clock customer support

- Convenient online submission

- Thorough peer review

- Inclusion in PubMed and all major indexing services

- Maximum visibility for your research

Submit your manuscript at www.biomedcentral.com/submit 